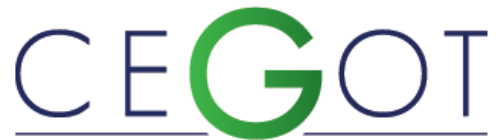

Centro de Estudos de Geografia e Ordenamento do Território
Geografia e Ordenamento do Território, Revista Eletrónica Centro de Estudos de Geografia e Ordenamento do Território http://cegot.org

AraúJo, Alan

Universidade Federal do Pará (UFPA) / Faculdade de Engenharia Florestal / Núcleo de Extensão em

Desenvolvimento Territorial

Rua Cel. José Porfírio, no 2515, 68.372-040, Altamira, Brasil alanaraujo@ufpa.br

\section{RODRIGUES, DIEGO}

Universidade Federal do Pará (UFPA) / Núcleo de Extensão em

Desenvolvimento Territorial

Rua Cel. José Porfírio, no 2515, 68.372-040, Altamira, Brasil

diego.florestalufpa@hotmail.com

SANTOS, LUIZ

Universidade Federal do Pará (UFPA) / Laboratório da

Faculdade de Engenharia Florestal

Rua Cel. José Porfírio, no 2515, 68.372-040, Altamira, Brasil

luizcarlosbs@ufpa.br

Paraense, Vinicius

Universidade Federal do Pará (UFPA) / Faculdade de

Engenharia Florestal

Rua Cel. José Porfírio, № 2515, 68.372-040, Altamira, Brasil

vcparaense@ig.com.br

\title{
Regularização fundiária e qualidade de vida dos assentados no projeto estadual de assentamento agroextrativista Gleba Majari I - Porto de Moz-PA
}

Regularization and quality of life of the seats in the agroextrativist estate settlement project Gleba Majari I - Porto de Moz-PA

Referência: Araújo, Alan et al. (2018). Regularização fundiária e qualidade de vida dos assentados no projeto estadual de assentamento agroextrativista Gleba Majari I - Porto de Moz-PA. Revista de Geografia e Ordenamento do Território (GOT), n. ${ }^{\circ} 14$ (setembro). Centro de Estudos de Geografia e Ordenamento do Território, p. 47-70, dx.doi.org/10.17127/got/2018.14.002

\section{RESUMO}

A regularização fundiária e a qualidade de vida são elementos fundamentais no sistema de reforma agrária, para isso as políticas públicas devem estar lado a lado com esse plano de desenvolvimento. Nessa perspectiva, essa pesquisa buscou mostrar como esse desenvolvimento está ocorrendo no Projeto Estadual de Assentamento Agroextrativista "Gleba Majari I" (PEAEX), instituído pelo governo do estado do Pará, no ano de 2009, para dar solução aos conflitos fundiários em terras públicas. Verificou-se que, a governança local constituída pelos moradores e liderada pela associação assegura a boa convivência interna, mas não garante a proteção física e os meios necessários para o desenvolvimento social e econômico do território do PEAEX.

Palavras-chave: Amazônia; Regularização Fundiária; PEAEX; Políticas Públicas; Desenvolvimento Rural. 


\section{ABSTRACT}

Land regularization and quality of life are fundamental elements in the agrarian reform system, for which public policies must be side by side with this development plan. In this perspective, this research sought to show how this development is occurring in the State Project of Agroextractivist Settlement "Gleba Majari I" (PEAEX), instituted by the government of the state of Pará in 2009, to solve land conflicts in public lands. It was verified that local governance constituted by the residents and led by the association ensures good internal coexistence, but does not guarantee the physical protection and the necessary means for the social and economic development of PEAEX territory.

Keywords: Amazon; Land regularization; PEAEX; Public policy; Rural Development.

\section{Introdução ${ }^{1}$}

A União utiliza o termo "assentamento" para designar todas as terras particulares que são desapropriadas e destinadas à reforma agrária. Quando o proprietário de um imóvel não atinge a eficiência desejada, a União, através do INCRA, retoma a área e a distribui para outras pessoas. Na esfera estadual, o uso do termo assentamento tem significado associado à realidade do estado do Pará, onde grande parte das terras é pública, portanto, não há necessidade de desapropriação. Assim, o que é chamado de "assentamento" é uma forma de Regularização Fundiária que busca a fixação do concessionário a terra, ou seja, o termo é empregado justamente para que a pessoa tenha os mesmos benefícios oferecidos aos demais concessionários pela União, conforme anteriormente abordado. Portanto, nesse primeiro momento, o processo denominado como assentamento pelo ITERPA difere do INCRA, pois, aquele não faz a realocação de pessoas, o que é feito é a Regularização Fundiária, pois a pessoa já mora no local, ou seja, a área ocupada pelo posseiro é apenas transformada em área titulada (ITERPA, 2009, p. 36).

A Instrução Normativa no 3, de 9 de junho de 2010, do ITERPA, dispõe sobre Projetos de Assentamento Estadual Agroextrativista (PEAEX), os caracterizando como local que se destina as populações que ocupam áreas dotadas de riquezas extrativas e que pratiquem a exploração sustentável dos recursos naturais e, complementarmente, se dediquem a atividades agrícolas de baixo impacto ambiental e a criação de animais de pequeno porte de onde geram renda por meio da produção do excedente (ITERPA, 2010).

\footnotetext{
${ }^{1} \mathrm{O}$ presente trabalho foi realizado com apoio financeiro do Núcleo de Extensão em Desenvolvimento Territorial (NEDET).
} 
Para que haja sustentabilidade e qualidade de vida no PEAEX, a participação do Estado é muito importante no que se refere às políticas públicas dentro do assentamento. No entanto, Teisserenc (2014), ao tratar de Unidades de conservação, diz que governança é uma ideia que reflete um território que conseguiu mobilizar atores na busca de uma dinâmica de desenvolvimento sustentável, que se manifesta, em particular, pela capacidade dos atores locais coproduzirem ações coletivas multissetoriais e conhecerem regras comuns capazes de facilitar a cooperação.

No entanto, a ideia expressa por Teisserenc (2014), em áreas de PEAEX, é de difícil execução, principalmente pela reduzida participação do estado como ator nos processos de organização e construção de estratégias. Nessas áreas, a gestão de responsabilidade do poder político, geralmente, é ineficiente para executar algumas atividades, por exemplo, monitoramento, organização de reuniões, criação de planos de manejo e fiscalização da área entre outros (PEREIRA, 2013).

Fernandes (2008) destaca que a obtenção de terras e o desenvolvimento de assentamentos são processos inseparáveis, que formam o principal fator de territorialização através da luta pela terra e da reforma agrária, evidenciando-se assim as conflitualidades que são expressas pelas relações de subalternidade e resistência.

Segundo Heredia et al. (2002, p. 33):

$\mathrm{O}$ acesso à terra permite às famílias uma maior estabilidade e rearranjos nas estratégias de reprodução familiar que resultam, de modo geral, em uma melhoria dos rendimentos e das condições de vida, especialmente quando se considera a situação de pobreza e exclusão social que caracterizava muitas dessas famílias antes do seu ingresso nos projetos de assentamento (HEREDIA et al., 2002, p.33).

De acordo com Bergamasco e Norder (1999), o assentamento rural é uma das formas objetivas de se fazer uma reforma agrária, pois:

[...] de maneira genérica, os assentamentos rurais podem ser definidos como a criação de novas unidades de produção agrícola, por meio de políticas governamentais visando o reordenamento do uso da terra, em benefício de trabalhadores rurais sem terra ou com pouca terra (BERGAMASCO; NORDER, 1999, p. 7).

No contexto da reforma agrária brasileira, o termo assentamento está relacionado a um espaço preciso em que uma população será instalada e, portanto, é uma transformação do espaço físico, cujo objetivo é a sua exploração agrícola (BERGAMASCO; BLANC-PAMARD; CHONCHOL, 1997). Como o seu significado remete à fixação do trabalhador na agricultura, envolve também a disponibilidade de condições adequadas para o uso da terra, como 
políticas públicas direcionadas a esse setor, e o incentivo à organização social e à vida comunitária.

Apesar da reforma agrária considerar a criação de projetos de assentamentos uma alternativa muito boa para o desenvolvimento dos espaços rurais, em algumas regiões como no Norte do Brasil, por exemplo, muitos projetos de assentamentos foram criados, porém, a aplicação ineficiente de políticas públicas afeta de forma significativa a qualidade de vida dos assentados. Por esse motivo, se faz necessário que os gestores desses modelos de projetos dediquem maior atenção a esses espaços. Adicionalmente, é muito importante indicar que, ao versar sobre qualidade de vida de assentados da reforma agrária, torna-se imprescindível abordar o tema desenvolvimento rural.

O presente estudo terá como foco o contexto social do PEAEX, e busca contribuir com o debate sobre regularização fundiária e qualidade de vida de assentados na Amazônia, através da descrição da realidade local investigada e averiguada sobre as transformações ocorridas naquela área, após a criação do assentamento.

Neste sentido, o objetivo do trabalho será averiguar como a regularização fundiária contribui com a melhoria da qualidade de vida e no acesso as políticas públicas pelos assentados no Projeto de Assentamento Estadual Agroextrativista Gleba Majari I, no município de Porto de Moz - Para.

\section{Material e Métodos}

\subsection{Caracterização da área de estudo e perfil dos entrevistados}

O PEAEX Gleba Majari I foi criado em 2009, pelo Instituto de Terras do Pará (ITERPA), para dar solução aos conflitos fundiários em terras públicas de domínio estadual. Está localizado geograficamente no município de Porto de Moz, Estado do Pará, microrregião do Baixo Amazonas, entre a Floresta Nacional de Caxiuanã e a Reserva Extrativista Verde Para Sempre, nas Margens do Rio Majari, são duas as formas de acesso ao assentamento, pelo leito do rio ou pela PA-163, o PEAEX fica a uma distância de $45 \mathrm{~km}$ da sede municipal de Porto de Moz (Figura 1). Em termos de superfície, corresponde a mais de 38 mil hectares, a maioria de floresta Ombrófila densa. Com a criação do PEAEX o direito de uso dos recursos passou a ser das famílias, administrado pela associação dos moradores. 


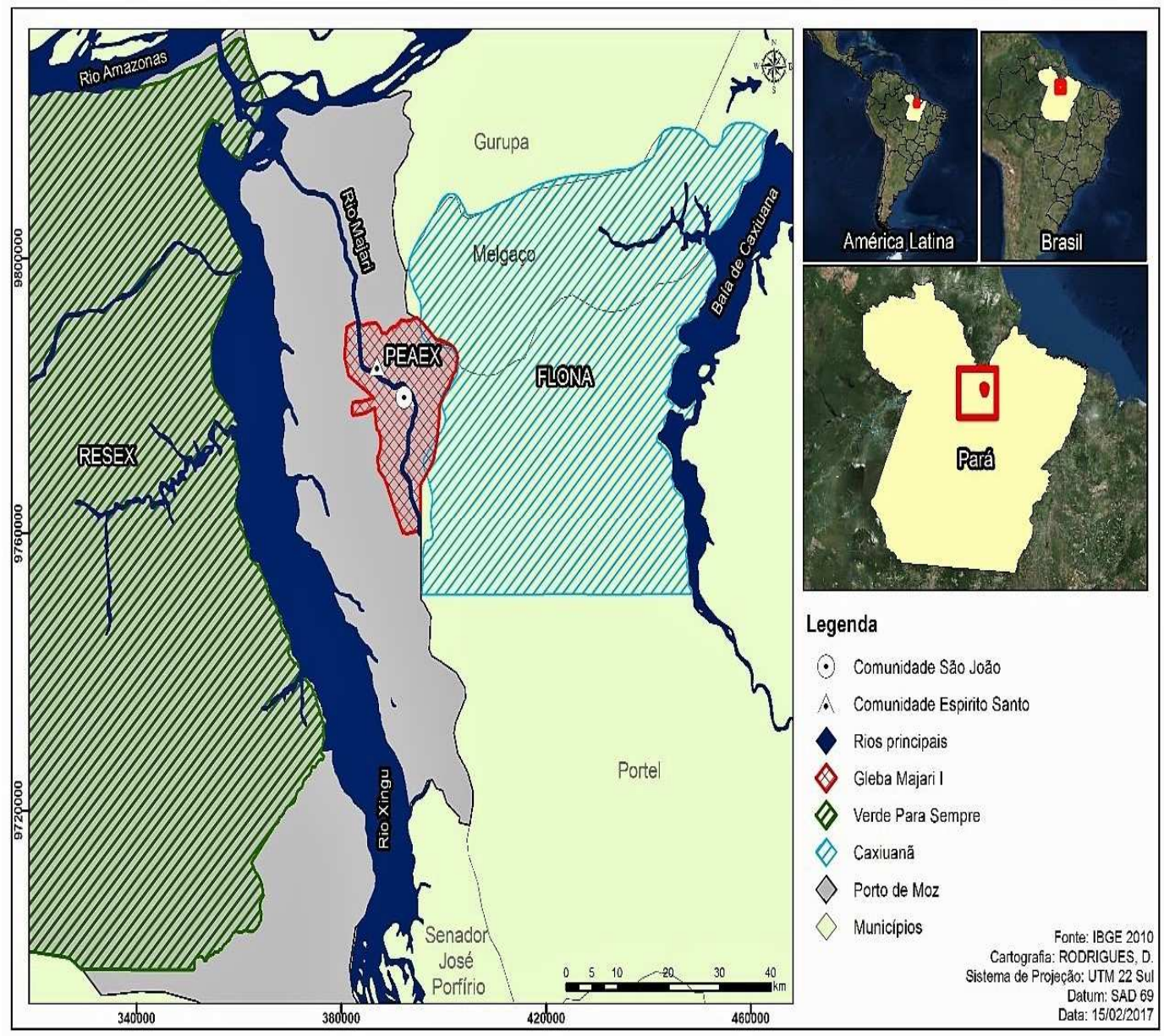

Figura 1 - Mapa de localização do PEAEX Gleba Majari

No assentamento, ao longo do rio, vivem 85 famílias as quais, basicamente, desenvolvem atividades agrícolas de subsistência (criação de animais de médio e pequeno porte, produção de culturas temporárias) e extrativismo (caça, pesca, extração de madeira) todas com uso de baixa tecnologia. A renda das famílias advém principalmente dos programas de transferência de renda do governo federal como bolsa família e aposentadoria.

\subsection{Definição da amostra}

Para caracterização e conhecimento acerca da regularização fundiária e qualidade de vida dos assentados no Projeto de Assentamento Gleba Majari I, foi trabalhado da seguinte forma, o assentamento está dividido em duas comunidades, comunidade Espirito Santo que possui um percentual de $36,4 \%$ dos assentados e comunidade São João que possui um percentual de $63,6 \%$ dos assentados. A distribuição espacial das localidades amostradas neste estudo encontra-se na (Figura 1). 


\subsection{Descrição do método, técnicas e ferramentas}

Para a coleta de dados foram realizadas entrevistas semiestruturadas com a aplicação de questionário e observação direta com registro fotográfico.

O método utilizado na pesquisa foi a abordagem qualitativa com o objetivo de compreender a dinâmica social do público alvo estudado.

De acordo com Godoy (1995):

De maneira diversa, a pesquisa qualitativa não procura enumerar e/ ou medir os eventos estudados, nem emprega instrumental estatístico na análise dos dados. Parte de questões ou focos de interesses amplos, que vão se definindo à medida que o estudo se desenvolve. Envolve a obtenção de dados descritivos sobre pessoas, lugares e processos interativos pelo contato direto do pesquisador com a situação estudada, procurando compreender os fenômenos segundo a perspectiva dos sujeitos, ou seja, dos participantes da situação em estudo (GODOY, 1995, p. 2).

Uma das técnicas utilizadas foi a entrevista semiestruturada que possibilitou uma melhor interação com os assentados na coleta de dados.

Como aborda Gil (2008):

A entrevista é seguramente a mais flexível de todas as técnicas de coleta de dados de que dispõem as ciências sociais. Daí porque podem ser definidos diferentes tipos de entrevista, em função de seu nível de estruturação. As entrevistas mais estruturadas são aquelas que predeterminam em maior grau as respostas a serem obtidas, ao passo que as menos estruturadas são desenvolvidas de forma mais espontânea, sem que estejam sujeitas a um modelo preestabelecido de interrogação (GIL, 2008, p. 130).

Outra técnica utilizada foi a de observação direta que auxilia na compreensão do meio.

Segundo Gil (2008):

[...] a observação constitui elemento fundamental para a pesquisa. Desde a formulação do problema, passando pela construção de hipóteses, coleta, análise e interpretação dos dados, a observação desempenha papel imprescindível no processo de pesquisa. É, todavia, na fase de coleta de dados que o seu papel se torna mais evidente. A observação é sempre utilizada nessa etapa, conjugada a outras técnicas ou utilizada de forma exclusiva (GIL, 2008, p. 119).

Para coleta de dados foram aplicados 68 questionários semiestruturados nas duas comunidades, 26 questionários na comunidade Espirito Santo e 42 na comunidade São João, no mês de julho de 2016. O questionário constituiu-se de perguntas fechadas, abertas e semiabertas, divididas nos seguintes itens: 1-Identificação da família, 2-Uso do Solo, 3- 
Extrativismo, 4-Organização Social, 5-Políticas Públicas e opinião sobre criação do assentamento.

Para Gil (2002):

[...] questionário é a técnica de investigação composta por um número mais ou menos elevado de questões apresentadas por escrito às pessoas, tendo por objetivo o conhecimento de opiniões, crenças, sentimentos, interesses, expectativas, situações vivenciadas, etc (GIL, 2002, p. 42).

Outra ferramenta utilizada foi o registro fotográfico que auxiliou com mais clareza na compreensão dos dados coletados em campo.

Segundo Vergara (2006):

A descrição de determinadas situações por meio de imagens é considerada mais profunda do que por meio de palavras. Imagens podem provocar lembranças e reflexões que acabariam se perdendo. Tal como o texto escrito, a fotoetnografia demanda um encadeamento. Caso contrário, corre-se o risco de apresentar apenas uma série de fotografias desconectadas, que não refletem o objetivo da pesquisa (VERGARA, 2006, p. 93).

A comunicação aconteceu diretamente com o proprietário do imóvel ou, na ausência deste, com outro membro (maior de idade) da família que conhecesse o histórico da propriedade e se considerasse capaz de responder às perguntas em campo, os dados foram tabulados utilizando a ferramenta online Google Docs, que permite a organização e análise dos dados, gerando a partir da inserção das informações gráficos e planilhas estatísticas que auxiliaram na interpretação e discussão dos resultados.

A vida no assentamento foi analisada e avaliada pelos assentados tomando como critério de referência bens que qualificam as experiências por eles vivenciadas. Deste modo, os bens que passaram a dispor após a conquista do assentamento servem como parâmetros para comparar a situação atual com as experiências anteriores naquele local, época marcada pela precariedade no acesso a um lugar de trabalho e de moradia.

A análise das entrevistas realizadas com os assentados possibilitou a identificação de determinados elementos, que foram tratados neste trabalho como indicadores de regularização fundiária e qualidade de vida das famílias do projeto do Projeto de assentamento Estadual Agroextrativista Gleba Majari I. Para a determinação desses indicadores foi utilizada como base a pesquisa denominada "A qualidade dos Assentamentos da Reforma Agrária Brasileira" realizada pela equipe técnica da (USP), da Food and Agriculture Organization of the United Nations (FAO) e do Instituto Nacional de 
Colonização e Reforma Agrária (INCRA), que teve como objetivo primeiro avaliar os aspectos qualitativos dos projetos de assentamento da reforma agrária brasileira, este trabalho representa uma estimável contribuição para a formulação de futuras políticas públicas que poderão auxiliar na escolha do melhor caminho a ser adotado para a resolução deste grande problema social (SPAROVEK 2003).

Entre esses elementos é possível destacar o acesso à terra, aos serviços públicos e as fontes de rendas. Esses indicadores surgiram a partir das entrevistas que resgatavam a trajetória de vida dos assentados, o que permitiu analisar fatos e processos importantes para a compreensão do que esses sujeitos valorizam e priorizam em suas vidas.

No quadro 1, estão elencados os elementos analisados neste trabalho como indicadores de regularização fundiária e qualidade de vida. Eles foram definidos, principalmente após a entrevista em campo com os assentados, e com os aspectos que consideravam essenciais para que alcançassem a segurança com a posse da terra e acesso aos diretos sociais básicos.

\begin{tabular}{|c|c|}
\hline REGULARIZAÇÃO FUNDIÁRIA & QUALIDADE DE VIDA \\
\hline Aquisição da terra & Acesso à educação \\
\hline Documentação da terra & Serviços de saúde \\
\hline Assistência técnica & Moradia \\
\hline & Abastecimento de água e luz elétrica \\
\hline & Economia e produção \\
\hline & Acesso a programas sociais \\
\hline
\end{tabular}

Quadro 1 - Indicadores analisados

\section{Resultados e Discussão}

\subsection{Regularização Fundiária}

\subsubsection{Aquisição da terra}

A maioria das propriedades no Projeto de Assentamento Estadual Agroextrativista Gleba Majari I, foram adquiridas a parir da década de 70 , do século $X X$, onde as primeiras famílias foram se formando na comunidade denominada São João. Na década de 80, outras famílias foram chegando e se instalando na comunidade denominada Espírito Santo. As principais atividades realizadas naquela época eram a retirada do leite da maçaranduba, a lavoura e a extração de madeira em tora. Sempre que alguém chegava na região, que hoje se encontra o Projeto de Assentamento, os assentados se reuniam e decidiam a permanência dela no 
local, caso a decisão fosse favorável, era selecionada uma área e demarcada através do "limite de respeito" ou "posse mansa", termos criados pelos assentados, onde ninguém poderia ter direito a posse daquela terra a não ser o morador destinado a ela. 0 único critério exigido para a permanência do novo assentado era trabalhar com a lavoura e cuidar da manutenção da terra. Muitas pessoas adquiriram terras através da compra de áreas de assentados que foram para a região, mas não se adaptaram com a localidade e com o estilo de vida, e acabavam vendendo a posse da terra que havia sido adquirida através da "posse mansa".

Segundo Heredia et al. (2002):

$\mathrm{O}$ acesso à terra permite às famílias uma maior estabilidade e rearranjos nas estratégias de reprodução familiar que resultam, de modo geral, em uma melhoria dos rendimentos e das condições de vida, especialmente quando se considera a situação de pobreza e exclusão social que caracterizava muitas dessas famílias antes do seu ingresso nos projetos de assentamento (HEREDIA et al., 2002, p.33).

Os resultados da pesquisa mostram que apesar do espaço territorial está institucionalizado pelo Governo Estadual, ainda prevalecem práticas antigas de aquisição de terras no assentamento, como por exemplo, a "posse mansa". Segundo mostra a pesquisa, a presença do órgão gestor, o ITERPA, é muito restrita no PEAEX, isso leva os assentados a tomarem conta dessa gestão territorial através da sua associação, com suas próprias regras internas de convivência.

A figura 2 mostra as formas como algumas famílias adquiriram a posse da terra antes da criação do Assentamento.

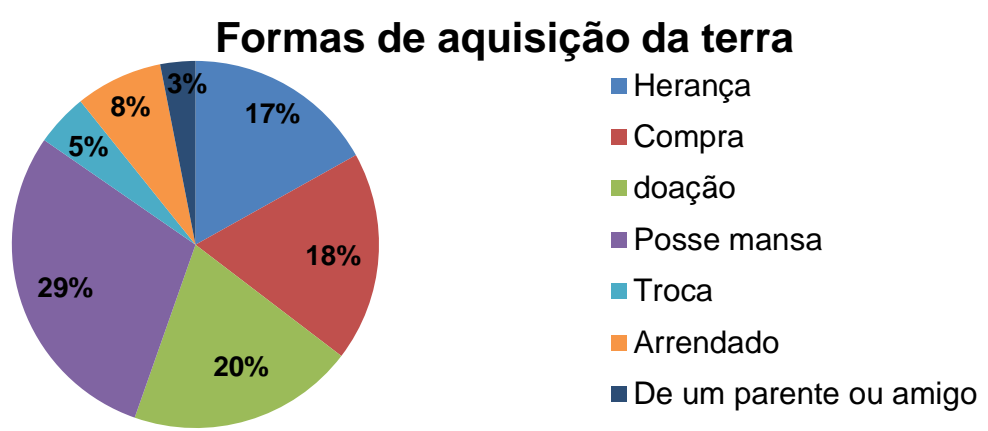

Figura 2 - Distribuição percentual das formas de aquisição da terra Fonte: Elaboração Própria (2018) 


\subsubsection{Documentação da Terra}

Os resultados da pesquisa mostram que, após a criação do assentamento, $84 \%$ dos assentados conseguiram adquirir o documento de concessão de uso da terra. Isso mostra que a criação do PEAEX foi importante para essa conquista dos assentados.

De acordo com o ITERPA (2009):

O objetivo buscado com a concessão em assentamentos é retirar as áreas destinadas para a pequena propriedade da especulação imobiliária e estimular as ações coletivas - tais como o associativismo - com o intuito de melhorar a qualidade e o preço da produção familiar. A meta do governo estadual, através das ações daquele órgão, é evitar que um assentamento de cem lotes se torne uma fazenda e a pessoa que recebeu a concessão saia daquela localidade, vá para outro destino e pleiteie uma nova área. Isso não quer dizer que esse lote estará "fora do mercado", porque ele pode ser vendido, desde que o comprador seja uma pessoa que respeite e atenda as características da concessão inicial (ITERPA, 2009, p. 43).

As famílias que ainda não possuem documentação da terra encontram-se nessa situação por razões como: falta de documentos pessoais (RG, CPF, entre outros), que, regularmente, os impossibilitavam de dar início ao processo de regularização documental da propriedade, além da falta de conhecimento dos procedimentos para retirada do documento (alguns assentados se quer sabem que tem direito de retirar a documentação da sua terra), e até, a falta de recursos financeiros para pagar os custos do processo.

De acordo com o Plano Nacional de Reforma Agrária (PNRA), a execução da reforma agrária, estaria apoiada em um conjunto de grandes ações classificadas em: programa básico, programas complementares e programas de apoio (ver quadro 2).

\begin{tabular}{|c|c|c|}
\hline Programa Básico & $\begin{array}{c}\text { Programas } \\
\text { Complementares }\end{array}$ & Programas de Apoio \\
\hline Assentamentos de & Regularização Fundiária & Cadastro Rural \\
trabalhadores rurais & Colonização \\
& Tributação da terra & $\begin{array}{c}\text { Astudos e Pesquisa } \\
\text { Apoio Jurídico } \\
\text { Desenvolvimento recursos } \\
\text { humanos }\end{array}$ \\
\hline
\end{tabular}

Quadro 2 - Programas de execução da reforma agrária no PNRA

Fonte: Elaboração Própria, adaptado de PNRA (2018)

De acordo com as informações apresentadas no quadro 2, pode-se perceber que 0 programa básico do PNRA consistia no assentamento de trabalhadores rurais, o qual deveria ocorrer preferencialmente em regiões já ocupadas pelos próprios trabalhadores e se 
fundamentar na oferta de terras, na promoção de uso das mesmas e no apoio à organização dos trabalhadores. Apesar das metas estabelecidas, o plano foi de grande importância para firmar a política de reforma agrária no Brasil, e foi inicialmente mais direcionado para assentamentos que tinham interesse em controlar conflitos e tensões em determinadas áreas de seus interesses. Porém, para Fernandes (2013, p. 221) o debate sobre reforma agrária deve evidenciar o elemento conflito como uma das dimensões essenciais para o desenvolvimento territorial. Evitando-se pensar esse processo a partir de uma visão meramente integradora, pois, as conflitualidades contribuem para que se alcance 0 desenvolvimento.

\subsubsection{Assistência técnica}

Quando perguntados sobre assistência técnica no PEAEX, após sua criação, $84 \%$ dos entrevistados responderam que nunca haviam recebido. Enquanto que, 16\% afirmaram terem sido atendidos com esse serviço, mas, apenas durante um curto período de tempo, quando iniciaram algumas atividades de plantio de lavouras temporárias. Ainda de acordo com os dados coletados, para esse mesmo grupo de assentados, a continuidade com a prestação de serviços de assistência técnica diretamente no campo não teve continuidade.

A criação do PEAEX abriu caminho para que os assentados cobrem do poder público à oferta de serviços de assistência técnica rural. Mesmo com o tímido resultado constato nesta pesquisa, sobre a prestação de serviços de assistência técnica naquela área, há uma confirmação de que houve esse serviço, que é necessário para o desenvolvimento da produção local. Para os entrevistados, a mudança desse cenário desfavorável aconteceria se houvesse uma maior e melhor atuação por parte da associação, que deve lutar por conquistas para o coletivo, e também dos órgãos responsáveis em garantir a oferta desses serviços.

Segundo ASBRAER (2010):

Os serviços de Ater têm abrangência de 95\% do território brasileiro, formando uma das mais expressivas redes para a construção coletiva do conhecimento e a promoção do desenvolvimento sustentável destes municípios. No entanto, apesar da evolução no orçamento e do esforço em prol da reestruturação desses serviços, somente um terço dos estados contam com entidades de Ater estruturadas e com um processo moderno 
de gestão. Os recursos federais ainda representam menos do que $10 \%$ dos investimentos feitos pelos governos estaduais, e os serviços chegam a apenas pouco mais de $30 \%$ dos agricultores brasileiros. (ASBRAER, 2010, p. 5).

Com base nos dados apresentados, é possível considerar que, após a criação do Projeto de Assentamento Estadual Agroextrativista Gleba Majari I houve avanços no contexto da regularização fundiária, com a concessão de posse e titulação da terra e o surgimento de assistência técnica, apesar de ainda não atender satisfatoriamente a demanda da população local. Para garantir a eficiência dessas ações é necessário que haja uma atuação intensa do ITERPA, que é o gestor daquele espaço. No entanto, isso não é percebido pelos assentados, que consideram ter recaído sobre si a responsabilidade de gerir o PEAEX.

\subsection{Qualidade de Vida}

\subsubsection{Acesso à Educação}

Neste trabalho, o entendimento de rural considera as suas particularidades, assim como orienta Araújo (2008), ao salientar que, o reconhecimento do rural deve basear-se na concepção, ao qual ele não pode ser definido por oposição, mas em sua relação com as cidades, devendo-se atentar sempre para a manutenção de suas especificidades. Um dos meios possíveis de mostrar e se utilizar dessas especificidades é a partir da educação. Uma educação aplicada ao cotidiano dessas pessoas, atendendo suas particularidades.

Quando questionados sobre a situação da educação no PEAEX, $100 \%$ dos entrevistados relataram que a consideram péssima no assentamento. Apesar de existir duas escolas, estando uma localizada na comunidade Espírito Santo e a outra na Comunidade São João, o grau de escolaridade ofertado é do 1 으 ao 9 o ano do ensino fundamental. Entre os problemas relatados, foi indicado que os materiais escolares disponíveis se encontram bastante deteriorados e desatualizados. Outro problema é a questão dos professores, que por não serem da localidade, possuem resistência em se instalarem e permanecerem no local. Mesmo havendo nas escolas um espaço, anexo, que é destinado para o acolhimento do professor durante a sua permanência na localidade, porém, alguns não se adaptam ao local, e acabam dando alguns dias de aula e voltam para a cidade, isso afeta o calendário escolar dos alunos do assentamento. Existe um projeto de construção de uma nova escola, que será 
um polo escolar no assentamento, que deve concentrar todos os alunos das duas comunidades, mas já faz 10 anos que o projeto existe, mas a obra se nunca foi se quer iniciada.

O acesso às escolas é feito todo pelo leito do rio Majari, um assentado com barco próprio realiza o trajeto dos alunos com o apoio da prefeitura de Porto de Moz, que cede o combustível para a realização desse transporte de alunos, mas isso ainda está muito longe do ideal para contribuir com a qualidade do ensino no assentamento.

Os dados da pesquisa revelam que $72 \%$ dos assentados do PEAEX tem apenas o ensino fundamental incompleto, e $16 \%$ informaram nunca ter frequentado a escola. Isso mostra que esse ainda é um dos desafios que precisa ser pelo menos mitigado no assentamento. $\mathrm{Na}$ figura 3 está projetado o resultado da verificação, desse componente, pela pesquisa.

\section{Grau de escolaridade PEAEX}

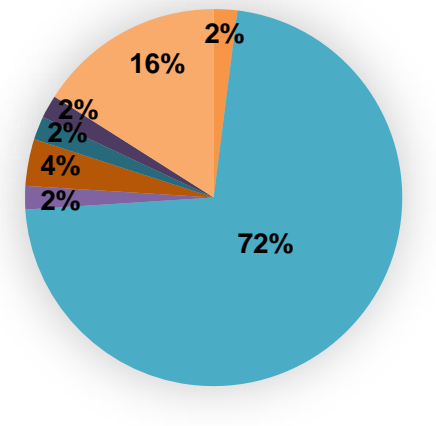

- Fundamental completo

- Fundamental incompleto

- Médio completo

médio incompleto

- Superior completo

- Curso técnico

Sem estudo

Figura 3 - Grau de escolaridade dos assentados do PEAEX.

Fonte: Elaboração Própria (2018)

Verificou-se que a maior parte das famílias assentadas (43\%) possui até a quarta série e $27 \%$ possui entre a quinta e oitava séries. Constatou-se que o reduzido nível de escolaridade da grande maioria das pessoas que se ocupam das atividades agrícolas é, sem dúvida, um enorme obstáculo para a melhoria da qualidade de vida no campo, uma vez que compromete o aumento da produtividade do trabalho, do crescimento dos salários e, consequentemente, da renda no campo, contribuindo para a permanência dos graves problemas da pobreza rural (HOFFMANN; NEY, 2004). E mesmo com esse cenário desfavorável, pouco foi feito para reverter essa situação.

Dados da Comissão Econômica para a América Latina (CEPAL), segundo Durston (1994), mostram que no Brasil camponês $55 \%$ dos rapazes têm menos de quatro anos de estudo. $\mathrm{A}$ 
precariedade da situação educacional das moças também é grave, mas, menos que a dos rapazes: $42 \%$ das jovens camponesas têm menos de quatro anos de estudo. Para que se tenha uma ideia da posição do Brasil na América Latina quanto a este aspecto, no Chile apenas $5 \%$ dos rapazes (e $4 \%$ das moças) estão nesta situação e mesmo no México as cifras são bem menos graves que no Brasil: $27 \%$ dos rapazes e $21 \%$ das moças (ABRAMOVAY, 2001). Tomando os dados de Abramovay (2001) com base, pode-se interpretar que a situação do PEAEX é preocupante, pois, o percentual está muito acima da média do Brasil.

Devido às dificuldades e limitações com a oferta de ensino no assentamento, muitos jovens vão morar na cidade para poder estudar, essa prática causa uma grande diminuição na força de trabalho do campo, tendo em vista que algumas famílias dependem da força de trabalho dos membros da unidade de produção familiar, mas, muitos dos jovens acostumam com a vida na cidade e não voltam para o campo. Como resultado disso, a idade do trabalho no campo vai aumentando e a quantidade e qualidade da produção diminuindo, causando sérios problemas para as famílias que sobrevivem da agricultura familiar. A figura 4 mostra que o principal motivo para a saída de jovens do assentamento é a busca por estudos na cidade (DALCIN; TROIAN, 2009).

\section{Motivo da saíde de jovens do PEAEX}

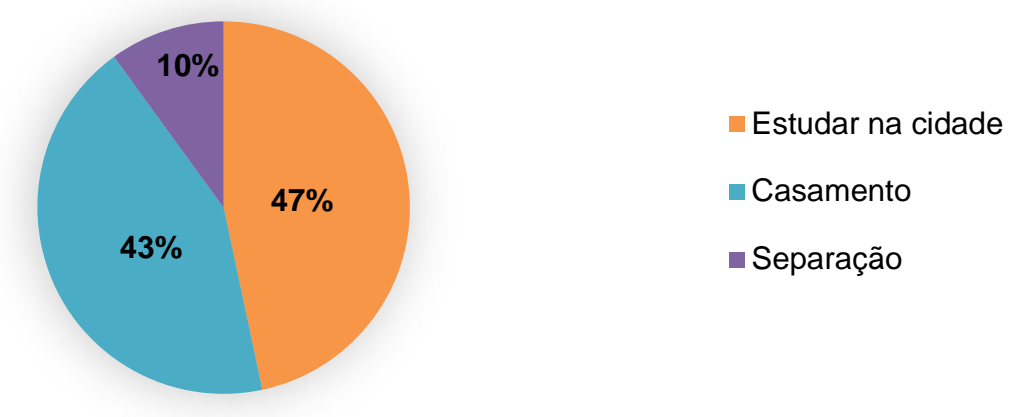

Figura 4 - Motivo da saída de jovens do PEAEX. Fonte: Elaboração Própria (2018)

\subsubsection{Serviços de Saúde}

É muito preocupante a situação da saúde no mundo inteiro. No Brasil, as políticas públicas voltadas a esse setor ainda são insuficientes para suprir toda a demanda do país, e principalmente para as pessoas de baixo poder aquisitivo que dependem muito dessa melhoria na saúde. A desigualdade ainda é muito grande, nesse sentido, são poucas pessoas 
que conseguem ter acesso a um sistema de saúde de qualidade, enquanto outros esperam atitude do poder público que Ihes possibilitem ter acesso a um serviço de saúde com qualidade.

Um importante passo na construção de uma saúde pública ocorreu graças a diversos movimentos que lutaram para que se consolidasse um sistema único de saúde, onde todos pudessem ter direitos iguais. No final da década de 80 foi consolidado o Sistema Único de Saúde (SUS) um avanço enorme para a população brasileira garantida pela constituição federal (RETKA et al., 2003).

Infelizmente no meio rural, questões relacionadas à saúde ainda é um entrave muito grande mesmo em meio a todas as políticas públicas, um quadro que tem que ser revisto pelo poder público para buscar soluções cabíveis para essa população, esse fato ocorre tanto em países desenvolvidos quanto em países em desenvolvimento.

Os resultados da pesquisa mostram que, de acordo com os assentados a saúde no assentamento é uma das questões mais difíceis, pois, não existe posto de saúde, ou mesmo um agente comunitário de saúde, tampouco há transporte para locomoção até o hospital, na cidade. Ou seja, não é oferecido no assentamento nenhum tipo de atendimento na área da saúde, mesmo esse direito estando previsto na legislação. Quando algum assentado fica doente, a única alternativa que ele tem é pedir dinheiro emprestado para poder comprar combustível para colocar na sua canoa e transportar a pessoa doente até um hospital na cidade de Porto de Moz. Existe um acesso para a cidade pela PA-163, que fica a aproximadamente $5 \mathrm{~km}$ da entrada do assentamento, alguns assentados quando dispõem de alguma condição financeira, fazem ligações às margens da PA-163 para tentar conseguir um meio de transporte rodoviário para levar o doente.

No assentamento não é possível realizar ligações telefônicas, pois, não existe torre de transmissão, isso dificulta ainda mais a vida dos assentados, quem não tem condições de pagar um transporte rodoviário, tem que levar o doente através de transporte fluvial pelo leito do rio até a cidade de Porto de Moz, alguns assentados moram mais distantes da sede municipal e podem levar até três horas somando o tempo de transporte fluvial até a entrada da PA-163 e o tempo de transporte rodoviário, os assentados que levam o doente direto por transporte fluvial podem levar até sete horas de viagem. 
Diversos estudos, entre eles: Arcury et al. (2005) e Travassos e Viacava (2007), mostram a importância dos fatores geográficos e espaciais no acesso e utilização de serviços de saúde pela população rural. Segundo Arcury et al. (2005), o fator geográfico é parte importante da estrutura conceitual da utilização de serviços de saúde nessa população, sofrendo grande influência também da capacidade de mobilidade das pessoas.

Para se ter acesso a serviços de saúde em áreas rurais, deve haver um balanço entre a necessidade dos assentados e a possibilidades deles de transporte.

Para Travassos e Viacava (2007), a redução das desvantagens no acesso e na utilização dos serviços de saúde para as populações rurais implica em melhorar a oferta de serviços e organizá-los de modo a atender às especificidades territoriais, culturais e sociais desses grupos populacionais. Por meio desta pesquisa, constatou-se que políticas públicas de saúde básica, não estão sendo implantadas, e isso resulta em sérios problemas para as comunidades, em todos os aspectos, seja no social, cultural ou econômico.

Com relação a esse problema, os assentados através da associação emitiram expedientes endereçados ao poder público municipal exigindo a oferta dos serviços básicos de saúde naquela localidade. Porém, até o momento em que essa pesquisa acontecia, o problema ainda não tinha sido solucionado.

\subsubsection{Moradia}

Outro ponto importante é a questão da moradia dos assentados no PEAEX, Segundo Grisa e Schneider (2015):

Mesmo previsto em várias Leis Federais, poucos recursos foram investidos pelo setor público em habitação rural no país até o ano de 2003 , com exceção dos investimentos realizados pelo Instituto Nacional de Colonização e Reforma Agraria (INCRA) nos assentamentos da reforma agraria e alguns investimentos em habitação rural realizados por Estados da federação, como e o caso do Rio Grande do Sul (GRISA; SCHNEIDER, 2015, p. 467).

A partir de 2003 um grupo de trabalho composto por atores sociais e políticos se reuniu para tratar da criação de um programa de habitação que atendesse as exigências do meio rural, foi proposta a criação do Programa de Habitação Rural (PHR), que se vinculou com o Programa Nacional de Habitação (PNH), em parceria com a Caixa Econômica Federal. Isso foi 
preciso pelo fato dos programas existentes de habitação rural oferecerem condições diferentes do programa de habitação urbano, o que causava essa distinção eram as condições de renda das famílias, que não acontecem de maneira fixa no meio rural, o que impedia essas famílias de se enquadrar nos financiamentos habitacionais nos moldes urbanos (GRISA; SCHNEIDER, 2015).

Em fevereiro de 2016 houve uma reunião no PEAEX com a participação de um representante da casa de governo federal, um representante do INCRA e representantes da associação do assentamento, a pauta da reunião tratava-se de um cadastro que seria feito para todas as famílias que residem no assentamento, para participar do projeto minha casa minha vida, onde seriam construídas casas de alvenaria e que iriam fornecer mais conforto para todas as famílias, mas, até a data da pesquisa nada ainda teria sido feito com relação a isso. $100 \%$ das moradias dentro do assentamento são construídas de madeira, algumas casas possuem piso com lajota, algumas com forro, outras têm parte das paredes de alvenaria e parte de madeira.

Algumas casas estão em estado crítico, oferecendo risco de acidentes para seus moradores, mas em entrevista com essas pessoas, elas alegaram que ou moram ali ou, infelizmente, não terão onde morar, e que não possuem condições para fazer melhorias na casa e tem que conviver com os riscos. Esse é outro ponto que mostra a reduzida atenção do poder público com a qualidade de vida daquelas pessoas. Através da figura 5 é possível visualizar imagens de residências no PEAEX.

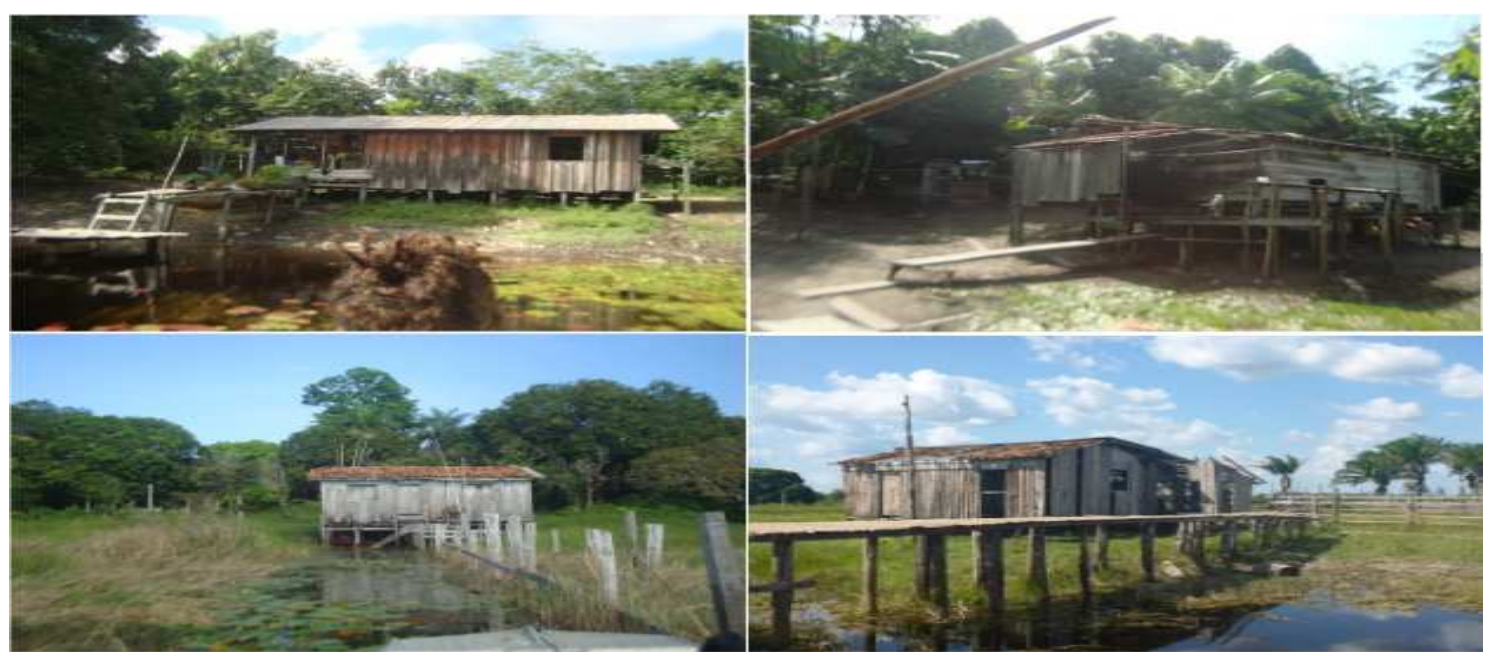

Figura 5 - Residências no Projeto de Assentamento Gleba Majari I 


\subsubsection{Abastecimento de água e luz elétrica}

Ao serem perguntados sobre o abastecimento de água, 90\% dos entrevistados responderam que não possuem água encanada, existe água encanada com poço e bombeamento apenas na vila da comunidade Espirito Santo e na vila da Comunidade São João (Figura 6). O sistema de abastecimento foi implantado pelos próprios assentados, a água que a maioria deles utiliza é a própria água do rio Majari, que por muitas vezes encontra-se em estado péssimo para o consumo. A água encanada é usada para beber, fazer a comida, lavar louça, lavar roupa e para dar aos animais. Antes da criação do PEAEX, muitas balsas madeireiras trafegavam no leito do rio, o que causava um grande problema, as águas ficavam sujas por dias e a maioria que dependia da água limpa, ficava sem o recurso natural em decorrência do tráfego de balsas. Com a criação do PEAEX a passagem de balsas naquela área foi interrompida, devolvendo o aspecto natural do rio e em consequência uma melhor qualidade da água. Algumas famílias utilizam filtros de barro na esperança de melhorar um pouco a qualidade dessas águas, outros que não tem condições acabam utilizando a água do jeito que pegam no rio sem nenhum tipo de tratamento, isso por muitas vezes acaba gerando problemas de saúde aos usuários.

Água é o elemento essencial para a manutenção da vida, um recurso limitado e que possui papel significativo no desenvolvimento econômico e social de uma região. Entretanto, os usos múltiplos e inadequados interferem na qualidade da água em diferentes escalas e acarretam a diminuição da sua quantidade em termos de qualidade. Além de ser um recurso limitado e dotado de valor econômico, a Política Nacional de Recursos Hídricos a define como um bem de domínio público e, assim sendo, todos têm o direito ao seu uso.

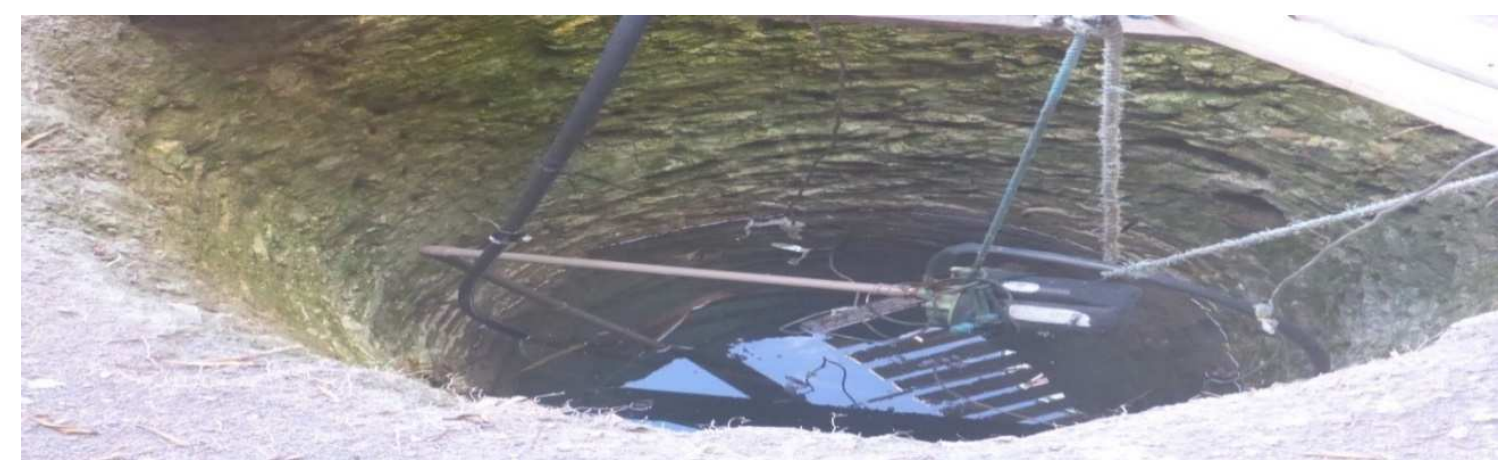

Figura 6 - Poço comunitário com bombeamento

Com relação à energia elétrica, apenas $46 \%$ dos assentados possuem energia em casa, enquanto que $54 \%$ não possui. Os assentados que possuem energia elétrica $86 \%$ são de 
forma particular, com a utilização de geradores que funcionam com o uso de combustível, e 14\% possuem energia da rede pública, estes se localizam a aproximadamente $2 \mathrm{~km}$ da PA163 e conseguiram puxar a instalação da estrada. Nas vilas das comunidades Espírito Santo e São João, é utilizado um gerador comunitário para as famílias que vivem lá, para a manutenção e para compra de combustível todos os assentados de cada vila se reúnem e fazem a compra do combustível necessário. (Figura 7). Já existiram propostas por parte da associação com pretensão de conseguir implantar o projeto luz para todos no assentamento, mas, em decorrência de ainda não ter havido consenso entre as duas comunidades, as propostas ainda não se consolidaram.

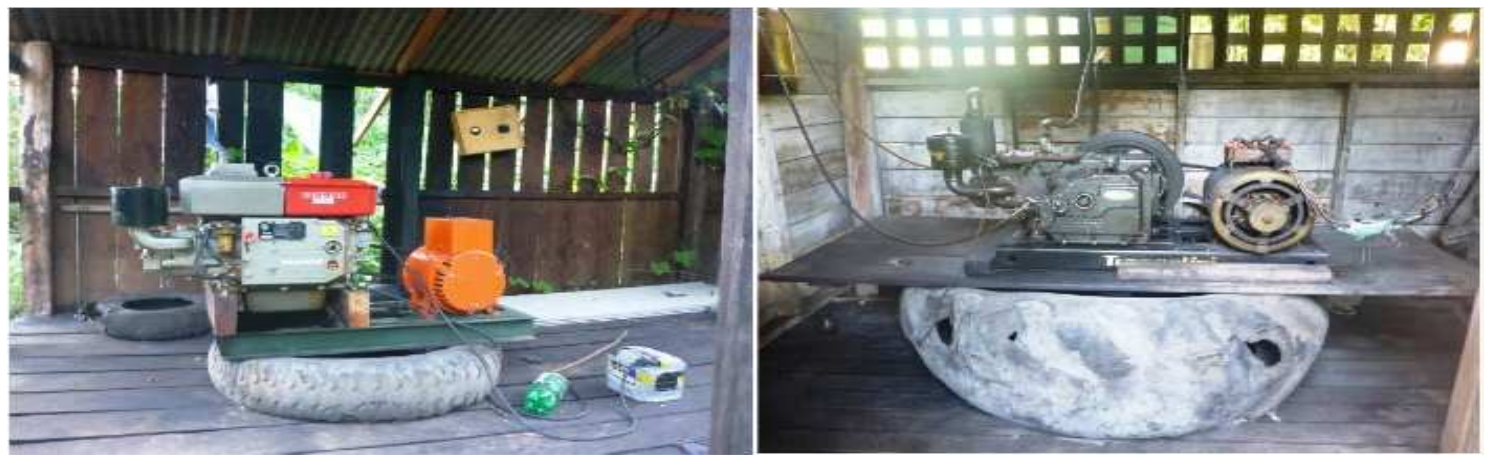

Figura 7 - Geradores de energia comunitário das vilas Espírito Santo e São João

\subsubsection{Economia e produção}

A economia do assentamento Gleba Majari I, em grande parte, é baseada na agricultura familiar, no plantio de culturas perenes e anuais e também na criação de animais. Mas, essa economia é afetada por diversos fatores, e características similares a que foi verificada no PEAEX são apontadas por Bianchini (2005), ao destacar que, as principais dificuldades para o desenvolvimento da produção agrícola familiar no Brasil são: baixa capitalização, dificuldade de acesso a linhas de créditos oficiais, e de acesso à tecnologia, além da disparidade produtiva inter-regional, acesso à assistência técnica para a produção rural, e o acesso aos mercados modernos.

Com a falta de políticas públicas como, o acesso à educação de qualidade que ocasiona o êxodo rural de jovens para a cidade, a assistência técnica para melhorar o conhecimento sobre a produção, o crédito rural para financiar maquinário para melhorar a terra, os meios de transporte para escoar a produção, a energia elétrica para a conservação dos alimentos, entre outros, a economia e o sistema de produção do PEAEX ficam comprometidos. Para 
Pitaguari e Lima (2005), políticas públicas que compreendem gastos públicos capazes de diminuir os custos de produção e viabilizar o setor produtivo melhoram as condições estruturais de crescimento e desenvolvimento da economia local. Sendo assim, as políticas públicas voltadas à promoção da agricultura familiar seriam capazes de diminuir algumas das dificuldades históricas para o desenvolvimento do setor como: a baixa capitalização, a dificuldade de acesso ao crédito, e o acesso aos mercados modernos pela adoção de novas tecnologias. Superadas tais dificuldades, o setor poderia então contribuir para a economia local e para o desenvolvimento das sociedades onde estão inseridos.

Quando questionados durante a pesquisa como eles se identificavam profissionalmente, $77,9 \%$ se autodeclararam agricultores, por terem nascido e se criado na roça, isso mostra a raiz do pequeno produtor que em meio as grandes dificuldades não abandonam sua forma de trabalhar e viver.

O Projeto de Cooperação entre a FAO e o INCRA, conforme aponta Bianchini (2005), dividiu os agricultores familiares em 4 tipologias de acordo com a renda, assim representados: tipo $A$ - agricultores familiares capitalizados; tipo $B$ - agricultores familiares em processo de capitalização; tipo $C$ - agricultores familiares em níveis de reprodução mínima; tipo $D$ agricultores familiares abaixo da linha de pobreza. A divisão por tipologia de agricultores familiares é referencial importante para a implementação de políticas públicas diferenciadas de acesso ao crédito a cada categoria. Nesse contexto, ao considerar os dados dessa pesquisa, torna-se possível afirmar que, os assentados do PEAEX, estão enquadrados como agricultores familiares tipo D, abaixo da linha da pobreza. A única fonte de renda relacionada com a produção que mais se expressa no assentamento é a plantação de mandioca, para produção de farinha, com um percentual de $90 \%$ das famílias trabalhando com essa cultura, que não gera uma grande fonte de renda, mas, ajuda na alimentação. Segundo os entrevistados, a maioria dos alimentos básicos dentro do assentamento não vem da sua produção familiar, eles são adquiridos na cidade, isso quando tem dinheiro para comprar, o resto é complementado com os recursos naturais, como caça e pesca.

Questionados sobre os principais problemas que dificultam a vida de quem mora no PEAEX, os que aparecem com mais expressão foram: atendimento à saúde com $40,3 \%$, meio de transporte com 37,1\%, acesso à educação com 27,4\%, assistência técnica com 19,4, e meio de comunicação com 11,3\%, mostrando a insatisfação dos assentados com esses fatores. 


\subsubsection{Acesso a programas sociais}

A fonte de renda do agricultor familiar pode se apresentar de duas formas: fonte de renda agrícola que se baseia na sua produção, que pode ser utilizada para seu próprio consumo e de sua família, como para adquirir renda comercial realizando a venda dessa produção. E fonte de renda não agrícola que é baseada no recebimento de salário por prestação de serviço, recebimento de aposentadoria, auxilio doença ou pensão através da previdência social (STOFFEL; COLOGNESE, 2005).

Grande parte das famílias no assentamento é beneficiária do programa bolsa família. 0 Programa foi instituído pelo Governo Federal, pela Lei no 10.836, de 9 de janeiro de 2004, regulamentado pelo Decreto $\mathrm{n}$ - 5.209, de 17 de setembro de 2004, alterado pelo Decreto $\mathrm{n}$ 은 6.157 de 16 de julho de 2007. Ele é gerenciado pelo Ministério de Desenvolvimento Social e Combate à Fome (MDS) e beneficia famílias pobres (com renda mensal por pessoa de R\$ 60,01 a $R \$ 120,00$ ), e extremamente pobres (com renda mensal por pessoa de até $R \$ 60,00$ ) (BRASIL, 2004). Considerada como renda não agrícola, esse auxilio ajuda várias famílias que estão realmente abaixo da linha da pobreza que é o caso de diversas famílias no assentamento.

Existem famílias que possuem o perfil para se tornarem beneficiárias do programa, porém, por falta de documentação pessoal e da terra, elas não conseguem realizar o cadastro. A associação está buscando soluções para garantir o acesso à documentação pelos assentados que não possuem, e com isso possibilitar o direito de acesso aos benefícios para aqueles que ainda não foram contemplados. Em contrapartida, a criação do PEAEX foi de grande ajuda para que as famílias pudessem ter acesso ao benefício bolsa família, no entanto, muito ainda precisa ser feito para melhorar essa situação.

Outro acesso à política pública social é a aposentadoria que alguns assentados estão recebendo. Segundo Debert (1999), a partir das transformações do envelhecimento postulase uma nova designação desta faixa etária de "terceira idade". Esta expressão infere uma contribuição positiva da velhice, pois não busca apenas resolver as dificuldades econômicas dos idosos, mas proporcionar cuidados socioculturais e psicológicos. Esta mesma autora afirma que para atender aos interesses das relações contemporâneas na modernidade, o conceito de terceira idade refere-se, em geral, àqueles idosos que ainda não atingiram a 
velhice "mais avançada", na faixa dos 55 aos 70 anos de idade e que ainda possuem uma vida saudável e tempo livre para o lazer, assim como para novas experiências nessa nova etapa da vida.

Alguns assentados recebem o benefício da aposentadoria no PEAEX, entretanto, cerca de $30 \%$ já atingiram a idade para ter direito ao benefício, mas esbarram no problema da falta de documentação pessoal, e ainda não conseguiram dar entrada ao processo de aposentadoria, além disso, outro problema é a falta de conhecimento sobre o direito ao benefício o que dificulta ainda mais a garantia desse direito aos assentados. Isso afeta bastante a vida de algumas famílias, que pela idade avançada não conseguem mais trabalhar no campo e dependeriam dessa renda da aposentadoria para continuar vivendo.

\section{Considerações Finais}

Mesmo com os esforços dos assentados para realizar a criação do PEAEX, para tentar resolver questões como regularização fundiária, garantir financiamentos para melhorar a produção, garantia de assistência técnica, políticas públicas de saúde, educação e moradia, infraestrutura com transporte para escoar produção, acesso a programas sociais, entre vários outros, ainda estão um pouco distantes de atenderem de forma satisfatória os assentados. Mesmo com o distanciamento do Estado e de outros atores externos, os assentados continuam na luta em busca dos seus direitos.

Famílias vivendo abaixo da linha da pobreza, por muitas vezes sem ter o que comer, passando por dificuldades que não deveriam, estão lá totalmente esquecidas, com a esperança que um dia os gestores e outros atores externos compareçam e deem a devida atenção que eles merecem. A pesquisa mostra que não há qualidade de vida adequada para essas famílias, muitas pensam em sair, mas permanecem porque acreditam na força da terra, querem permanecer até o fim mesmo diante de todas as dificuldades. Mas isso não os impede de exercer seu papel na gestão do seu território, com uma associação bem estruturada e com a força de vontade de grande parte das famílias, os assentados do PEAEX 
estão buscando se inserir no contexto de desenvolvimento rural e qualidade de vida na região.

Mesmo com todos os problemas, os assentados através da associação tentam assegurar a boa convivência interna, mas isso não garante a proteção física e os meios necessários para o desenvolvimento social e econômico do território constituído no PEAEX. A associação está se articulando e buscando evocar a participação das agências oficiais (federal, estadual e/ou municipal) para o fortalecimento da governança local.

\section{Referências bibliográficas}

ABRAMOVAY, R. O futuro das populações rurais. Porto Alegre, Ed. UFRGS,2001.

ARCURY, T. A; GESLER, W. M. PREISSER, J. S.; SHERMAN, J. SPENCER, J.; PERIN, J. The Effects of Geography and Spatial Behavior on Health Care Utilization among the Residents of a Rural Region. Health Services Research, v. 40, n.1, February, 2005.

ARAUJO, J. D. S. A. A escola rural brasileira; vencendo os desafios nos caminhos e descaminhos do tempo. Disponível em: www.ufpi.br/mesteduc/eventos/ivencontro/GT1/escola rural.pdf. Acessado em: BIAZZO, P. P. Campo e rural, cidade e urbano: distinções necessárias para uma perspectiva crítica em geografia agrária. 4으 Encontro Nacional de Grupos de Pesquisa - ENGRUP, São Paulo, pp. 132-150, 2008.

ASBRAER. Serviços de ATER para o Brasil CONTEPORÂNEO. 1. Ed. DF, 2010, 20 p.

BERGAMASCO, S. M. P. P; NORDER, L. A. C. Os impactos regionais dos assentamentos rurais em São Paulo (1996-1997). In: A formação dos assentamentos rurais no Brasil: processos sociais e políticas públicas / organizado por Medeiros, L. S. e Leite, S. Porto Alegre/Rio de Janeiro: Ed. Universidade/UFRGS/CPDA, 1999.

BERGAMASCO, S. M. P. P; BLANC-PAMARD, C.; CHONCHOL, M. E. Por um Atlas dos assentamentos brasileiros: espaços de pesquisa. Rio de Janeiro: DL/Brasil, 1997.

BIANCHINI, V. O universo da agricultura familiar e sua contribuição ao desenvolvimento rural. Rio de Janeiro, 2005. Curso de Aperfeiçoamento em Agroecologia. REDCAPA - Rede de Instituições Vinculadas à Capacitação em Economia e Política Agrícola da América Latina e Caribe.

BRASIL. Lei Federal no 10.836, de 9 de janeiro de 2004. Dispõe sobre o Programa Bolsa Família e dá outras providencias. Disponível em: <http://www.planalto.gov.br/ccivil_03/_ato2004-2006/2004/lei/l10.836.htm>. Acesso em 20 de julho de 2017.

DALCIN, D; TROIAN, A. Jovem no meio rural a dicotomia entre sair e permanecer: um estudo de caso. Seminário Nacional: Sociologia \& Política, 1., 2009, Curitiba. Anais eletrônicos... Disponível em: <http://www.humanas.ufpr.br/site/evento/SociologiaPolitica/GTs-ONLINE/GT7\%20online/jovem-meio-ruralDioneiaDalcin.pdf >. Acesso em: 03 nov. 2017.

DEBERT, G. G. A reinvenção da velhice: socialização e processos de reprivatizarão do envelhecimento. São Paulo: Ed. Edusp/Fapesp, 1999.

DURSTON, J. Juventude do campo, modernidade e democracia: Desafio para os Noventa. In: Juventude e Desenvolvimento do campo no Cone sul Latino americano. Série Documentos Temáticos. RS. Brasil. Junho 1994. 
FERNANDES, B. M. Entrando nos territórios do Território. In: PAULINO, Eliane Tomiasi; FABRINI, João Edmilson. Campesinato e territórios em disputa. São Paulo: Expressão Popular, 2008. p. 273-302.

FERNANDES, B. M. Questão Agrária: Conflitualidade e Desenvolvimento Territorial. In: STEDILE, João Pedro (Org.); ESTEVAM, Douglas (assistente de pesquisa). A Questão Agrária no Brasil: O debate na década de 2000. - 1.ed.-São Paulo: Expressão Popular, 2013. p. 173-238.

GIL, A. C. Como elaborar projetos de pesquisa. 2002, p. 45.

GIL, A. C. Métodos e técnicas de pesquisa social. 6. Ed. - São Paulo: Atlas, 2008.

GODOY, A. S. Introdução a Pesquisa Quaitativa e Suas Possibilidades. Revista de Administração de Empresas, São Paulo, v. 35, n. 2, p. 57-63, mar./abr. 1995.

GRISA, C; SCHNEIDER, S. Políticas Públicas de Desenvolvimento Rural no Brasil. Porto Alegre: Editora da UFRGS, 2015. 624 p.

HEREDIA, B; MEDEIROS, L; PALMEIRA, M; CINTRÃO, R; LEITE, S, P. Análise dos impactos regionais da reforma agrária no Brasil. Estudos Sociedade e Agricultura, v. 18, p.73-111, abr. 2002.

HOFFMANN, R; NEY, M. G. Desigualdade, escolaridade e rendimentos na agricultura, indústria e serviços, de 1992 a 2002. In: XLII Congresso Brasileiro de Economia e Sociologia Rural: Cuiabá, 2004. Anais... Cuiabá, MT: UFMT; Embrapa Florestas, 2004, Cd-rom. 28 p.

ITERPA. Regularização Territorial: a regularização fundiária como instrumento de ordenar o espaço e democratizar o acesso à terra. Texto, Instituto de Terras do Pará; Organização, Jane Aparecida Marques e Maria Ataide Malcher. Belém: ITERPA, 2009. 74 p.

ITERPA. Instrução Normativa no 3, de 9 de junho de 2010. Dispõe sobre o processo de criação dos Projetos Estaduais de assentamentos. Instituto de Terras do Pará. Diário Oficial do Estado, Belém, PA, n. 31.766, p. 1621, 05 de Out. de 2010. Disponível em:<http://www.ioepa.com.br/diarios/2010/2010.10.05.DOE.pdf>. Acesso em: 10 nov. 2016.

PEREIRA, L. B. Evolução da pecuária bubalina e a transformação dos ecossistemas na resex verde para sempre: um olhar a partir da análise retrospectiva. Programa de Pós-Graduação em Agriculturas Amazônicas. NEAF/PPGAA/UFPA, Bélem: 2013. 179p.

PITAGUARI, S. O; LIMA, J. F. As idéias keynesianas e o crescimento do produto nas economias locais. Interações: Revista Internacional de Desenvolvimento Local, Campo Grande, v. 6, n. 10, p. 11-20, 2005.

RETKA, N; CENTENARO, A; GREGÓRIO JÚNIOR, H. I; RIZZOTTO, M. L. F. A saúde no Brasil a partir da década de 80: retrospectiva histórica e conjuntura atual. Seminário Nacional: Estado e Políticas Sociais no Brasil, 3., 2003, Cascavel. Anais eletrônicos... Disponível em: <http://cacphp.unioeste.br/projetos/gpps/midia/seminario1/trabalhos/Saude/eixo1/42NilvoRetka.pdf>. Acesso em: 03 nov. 2017.

SPAROVEK, G. A qualidade dos assentamentos da reforma agrária brasileira. - São Paulo: Páginas \& Letras Editora e Gráfica, 2003.

STOFFEL, J. A; COLOGNESE, S. A. Formas de organização produtiva da pequena produção agrícola familiar no Oeste do Paraná: potencialidades e obstáculos. Cadernos de Economia, Chapecó, v. 9, n. 16, p. 25-42, 2005.

TEISSERENC, P. Governança territorial em reservas extrativistas. Revista Pós Ciencias Sociais. V.11, n. 22, $\mathrm{jul} / \mathrm{dez} .2014$.

TRAVASSOS, C; VIACAVA, F. Acesso e Uso de Serviços de Saúde em Idosos Residentes em Áreas Rurais, Brasil, 1998 e 2003. Cad. de Saúde Pública, Rio de Janeiro, n. 23, v. 10, p. 2490-2502, out 2007.

VERGARA, S. C. Projetos e relatórios de pesquisa em administração. São Paulo: Atlas, 2006. 